\title{
Six month follow up in communicable versus non-communicable diseases in an Iraqi refugee camp
}

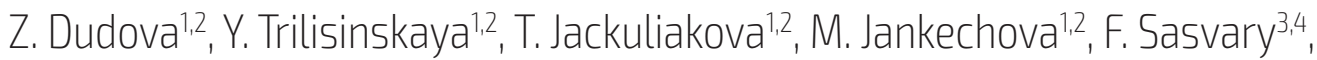 \\ A. Mátel5, B. Takac 3,4, A. Krizanova1,2, J. Otrubova1,2, M. Komlosi',2, J. Benca1,2,

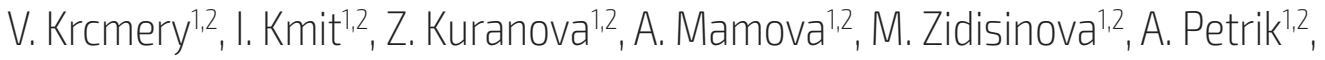 \\ I. K. Alhaj Ali,
}

Original Articles

${ }^{1}$ B1. Z. Schelling clinic refugee camp. IB-2, Autonomous republic of Kurdistan

2 SEUC, MH and PhD Program, Erbil, Autonomous Republic of Kurdistan, Iraq

${ }^{3}$ Internal Department, General Hospital, Sahy, Slovakia

${ }^{4}$ Faculty of Health Slovak Medical University in Bratislava located in Banska Bystrica, Slovakia

5 St. John Nepomuk Neumann Institut SEU Pribram, Czech Republic

\section{Correspondence to:}

B1. Z. Schelling clinic, Erbil, Autonomous Republic of Kurdistan, Iraq

Submitted: 11.6.2016

Revised: 26.8 .2016

Accepted: 14.9.2016

\section{Reviewers:}

D. Kimuli

Catholic University of Eastern Africa, Nairobi, Kenya

J. Benca

Slovak Tropical Institute, St. Elizabeth University Bratislava, Slovakia

\section{Key words:}

Diabetes, Hypertension, Respiratory tract infections.

\section{Key message:}

Despite overcrowding conditions, Iraqi refugees do not suffer from communicable diseases in comparison to non-communicable illnesses.

CSWHI 2016; 7(3): 38-41; DOI 10.22359/cswhi_7_3_10 @ 2016 Clinical Social Work and Health Intervention

\section{Abstract:}

Introduction: Massive internal displacement of Iraqi civilian in Autonomous Kurdistan led to humanitarian catastrophe. The aim of the study is to assess comparison of communicable to non-communicable diseases among the internally displaced in Autonomous Kurdistan.

Patients and Methods: In an open cohort two arm study, children vs adults and communicable vs non-communicable diseases, the occurrence of infectious and non-infectious diseases were compared during the first 6 months of 2016. Within the selected population of refugees 
from the Mosul area of Northern Iraq and a timeframe of 6 months we performed 2,844 health consultations.

Results: 2,844 patients have been seen from a 9,000 size camp in the 6 months from January to June 2016: 212 patients were children; 1,632 adults. Acute Respiratory Infections were the most frequently diagnosed infection diseases, but represented only a minority among visits (325 of 2,844 cases, 12.4\%). The rest, $87.6 \%$, were war-conflict related diseases such as hypertension, depression, diabetes.

Conclusion: Non-infectious diseases prevalent among Iraqi refugees include asthma, diabetes, hypertension and reactive osydiatric disorders.

\section{Introduction}

After Mosul had been occupied by DAESH - forces of the self-declared Islamic State (IS) - about 1 million of the 3 million population was internally displaced (IDP) into UNHCR camps in the northwest of the Autonomous Republic of Kurdistan. One of the largest and oldest is the IB-2 Camp with capacity for 10,000 inhabitants where approximately 9,000 IDPs are still residing (1-5). The aim of this communication is to compare underlying diseases in both groups of IDP refugees in 2016.

\section{Patients and Methods}

In an open cohort two arm study: children vs adults and communicable vs non-communicable diseases, the occurrence of infectious and non-infectious diseases were compared during the first 6 months of 2016. We performed 2,844 health consultations within the selected population of refugees from the Mosul area of Northern Iraq within the 6 months timeframe.

\section{Results}

In the 6 months from January to June 2016, 2,844 patients from the 9,000 have been seen; 212 patients were children and 1,632 adults. Acute Respiratory Infections were the most frequently diagnosed infection diseases but represented only a minority among visits (325 of 2844 cases, 12.4\%).
The rest $(87.6 \%)$ were war-conflict related diseases such as hypertension, depression, diabetes.

\section{Patients and Methods}

Six months daily follow-up was performed with the population of Iraqi refugees from Mosul in an open cohort study in the single internally displaced type camp in Autonomous Kurdistan.

\section{Results and Discussion}

In the 6 months from January to June 2016, 2,844 patients from the 9,000 have been seen; 212 were children and 1,632 adults. Acute Respiratory Infections were the most frequently diagnosed infectious diseases, but represented only a minority of 325 from 2,844 cases $(12.4 \%)$. The rest $(87.6 \%)$ were war-conflict related diseases such as hypertension, depression, diabetes.

As seen from Table 1, infectious diseases (all but 7 of 325) were mostly respiratory infections (98\%). This is a sign of a good hygienic standard and high public health level in the camp compared to the displacement after genocide in Rwanda in 1945 where a cholera outbreak had been reported (1-5); or after disaster relief on Haiti in 2010 were more than 300,000 cases of cholera have been observed among IDP after the earthquake (6). Also, other types of disease such as scabies were quite rare compared 
to the "migrating" refugees on the Balkan Route (7). Suspected cases of diphtheria were not confirmed. Only 4 cases of Acute and Bloody Diarrhea among 2,844 visits have been observed $(0.1 \%)$. Non-communicable diseases were highly prevalent $(88 \%)$.

Tab.1 Clinic of Bl. Zdenka Schelling, Erbil - spectrum of patients

\begin{tabular}{|c|c|c|c|c|}
\hline & \multicolumn{2}{|c|}{ No of cases $<5 Y$} & \multicolumn{2}{|c|}{ No of cases $>=5 \mathrm{Y}$} \\
\hline & Male & Female & Male & Female \\
\hline \multicolumn{5}{|l|}{ Respiratory Diseases } \\
\hline $\begin{array}{l}\text { 1.Accute (upper) } \\
\text { respiratory infection }\end{array}$ & 54 & 46 & 105 & 120 \\
\hline $\begin{array}{l}\text { 2.Acute (lower) respiratory } \\
\text { inf. (suspected Pneumonia) }\end{array}$ & 3 & 2 & 8 & 1 \\
\hline \multicolumn{5}{|l|}{ Water Borne Diseases } \\
\hline 1.Accute Diarrhea & 1 & $\mathbf{0}$ & 1 & 1 \\
\hline 2.Bloody Diarrhea & 1 & $\mathbf{0}$ & $\mathbf{0}$ & $\mathbf{0}$ \\
\hline 3. Acute Watery Diarrhea & $\mathbf{0}$ & $\mathbf{0}$ & $\mathbf{0}$ & $\mathbf{0}$ \\
\hline $\begin{array}{l}\text { 4.Acute Jaundice } \\
\text { Syndrome }\end{array}$ & $\mathbf{0}$ & $\mathbf{0}$ & $\mathbf{0}$ & $\mathbf{0}$ \\
\hline \multicolumn{5}{|l|}{ Vaccine Preventable Diseases } \\
\hline 1.Acute Flaccid Paralysis & $\mathbf{0}$ & $\mathbf{0}$ & $\mathbf{0}$ & $\mathbf{0}$ \\
\hline 2.Suspected Measles & $\mathbf{0}$ & $\mathbf{0}$ & $\mathbf{0}$ & $\mathbf{0}$ \\
\hline 3.Suspected Meningitis & $\mathbf{0}$ & $\mathbf{0}$ & 1 & 1 \\
\hline 4.Suspected Diphtheria & $\mathbf{0}$ & $\mathbf{0}$ & $\mathbf{0}$ & 1 \\
\hline 5.Suspected Pertussis & $\mathbf{0}$ & $\mathbf{0}$ & $\mathbf{0}$ & $\mathbf{0}$ \\
\hline $\begin{array}{l}\text { 6.Suspected Neonatal } \\
\text { Tetanus }\end{array}$ & $\mathbf{0}$ & $\mathbf{0}$ & $\mathbf{0}$ & $\mathbf{0}$ \\
\hline \multicolumn{5}{|l|}{ Other Communicable Diseases } \\
\hline 1.Unexplained Fever & $\mathbf{0}$ & $\mathbf{0}$ & $\mathbf{0}$ & $\mathbf{0}$ \\
\hline 2.Suspected Leishmaniosis & $\mathbf{0}$ & $\mathbf{0}$ & $\mathbf{0}$ & $\mathbf{0}$ \\
\hline $\begin{array}{l}\text { 3. Suspected Hemorrhagic } \\
\text { fever }\end{array}$ & $\mathbf{0}$ & $\mathbf{0}$ & $\mathbf{0}$ & $\mathbf{0}$ \\
\hline $\begin{array}{l}\text { 4.Skin Infections } \\
\text { (Scabies) }\end{array}$ & $\mathbf{0}$ & $\mathbf{0}$ & 2 & 1 \\
\hline 5.Animal Bites & $\mathbf{0}$ & $\mathbf{0}$ & $\mathbf{0}$ & 1 \\
\hline 6.Acute Malnutrition & $\mathbf{0}$ & $\mathbf{0}$ & $\mathbf{0}$ & $\mathbf{0}$ \\
\hline $\begin{array}{l}\text { 7.Other unusual } \\
\text { communicable Diseases }\end{array}$ & $\mathbf{0}$ & $\mathbf{0}$ & $\mathbf{0}$ & 1 \\
\hline $\begin{array}{l}\text { 8. Total number of all } \\
\text { consultations }\end{array}$ & 1 & 3 & 4 & 17 \\
\hline
\end{tabular}




\begin{tabular}{|l|c|c|c|c|c|}
\hline & $\begin{array}{c}\text { Male } \\
\text { No of cases } \\
<\mathbf{5 Y}\end{array}$ & $\begin{array}{c}\text { Female } \\
\text { No of cases } \\
<\mathbf{5 Y}\end{array}$ & $\begin{array}{c}\text { Male } \\
\text { No of cases } \\
<\mathbf{5 Y}\end{array}$ & $\begin{array}{c}\text { Female } \\
\text { No of cases } \\
<\mathbf{5 Y}\end{array}$ & Total numb. \\
\hline $\begin{array}{l}\text { Hypertension: } \\
\text { Diagnose }\end{array}$ & $\mathbf{0}$ & $\mathbf{0}$ & $\mathbf{4 5}$ & $\mathbf{7 7}$ & $\mathbf{1 2 2}$ \\
\hline $\begin{array}{l}\text { Hypertension: } \\
\text { Check up }\end{array}$ & $\mathbf{4}$ & $\mathbf{0}$ & $\mathbf{3 4 0}$ & $\mathbf{4 1 4}$ & $\mathbf{7 5 8}$ \\
\hline $\begin{array}{l}\text { Diabetes: } \\
\text { Diagnose }\end{array}$ & $\mathbf{0}$ & $\mathbf{0}$ & $\mathbf{4 5}$ & $\mathbf{7 7}$ & $\mathbf{1 2 2}$ \\
\hline $\begin{array}{l}\text { Diabetes: Check } \\
\text { up }\end{array}$ & $\mathbf{3}$ & $\mathbf{0}$ & $\mathbf{1 4 4}$ & $\mathbf{2 1 8}$ & $\mathbf{3 6 5}$ \\
\hline $\begin{array}{l}\text { Total \# of all } \\
\text { consultations }\end{array}$ & $\mathbf{1 0 7}$ & $\mathbf{1 0 5}$ & $\mathbf{1 , 0 6 2}$ & $\mathbf{1 , 5 7 0}$ & $\mathbf{2 , 8 4 4}$ \\
\hline
\end{tabular}

\section{Conclusions}

Massive internal displacement of Iraqi civilians into Autonomous Kurdistan led to humanitarian catastrophe. The aim of this study was to provide a comparison of communicable and non-communicable diseases among internally displaced people in Autonomous Kurdistan. Non- communicable diseases have high prevalence among populations of Iraqis from Mosul to Irbil.

\section{References}

1. PRESTILEO T, Di LORENZE F, Corrao S: Infectious Diseases among African irregular migrants in Italy. Just an individual problem? Clin. Soc. Work 2015, 5, 45

2. WICZMANDYOVA D., MURGOVA A., The life of diabetics, life with diabete,
Book.Clear. Michalovce ISBN 978-809711629255.2012 , pp 67

3. ESCOBIO F, ECHEVARRIA J, RUBAKI S, VINICZAI V: Health assistance of displaced people along the Balkan Route, Lancet 2015, 386, Dec.19, 2475

4. WICZMANDYOVA D, TKACOVA, L, MURGOVA, M: Proceedings Slov. Med. Univ.: The Socio Economic aspect of Migrations, ISBN 978-80-89352-47-0, pp.62-70

5. KRCMERY V, KALAVSKY E: $A T B$ and ATP resistance in ATB free pneumonia $\mathrm{Neu}-$ roendocrinology Letters 2007, 29

6. SILHAROVA B, SUVADA J, FRANEKOVA M, NOGE A, MIKOLASOVA G: $M a-$ laria in hyperendemic region, Neuroendocrinology Letters. 34, 2013, s1 38-43 